\title{
Hollow IF-MoS $2 /$ r-GO Nanocomposite Filled Polyimide Coating with Improved Mechanical, Thermal and Tribological Properties
}

\author{
Jian Wu ${ }^{1,2}$, Xiang Yin ${ }^{1}$, Liwen Mu ${ }^{1,2}$, Xin Feng ${ }^{1, *}$, Xiaohua $\mathrm{Lu}^{1}$ and Yijun Shi ${ }^{2, *}$ \\ 1 State Key Laboratory of Materials-Oriented Chemical Engineering, College of Chemical Engineering, \\ Nanjing Tech University, Nanjing 211816, China; jian.wu@njtech.edu.cn (J.W.); yinxiang@njtech.edu.cn (X.Y.); \\ fujin.1234@163.com (L.M.); xhlu@njtech.edu.cn (X.L.) \\ 2 Division of Machine Elements, Luleå University of Technology, 97187 Luleå, Sweden \\ * Correspondence: xfeng@njtech.edu.cn (X.F.); yijun.shi@ltu.se (Y.S.)
}

check for updates

Citation: Wu, J.; Yin, X.; Mu, L.; Feng, X.; Lu, X.; Shi, Y. Hollow IF-MoS 2 / r-GO Nanocomposite Filled Polyimide Coating with Improved Mechanical, Thermal and Tribological Properties. Coatings 2021, 11, 25. https://doi.org/

10.3390/coatings 11010025

Received: 24 November 2020 Accepted: 21 December 2020 Published: 28 December 2020

Publisher's Note: MDPI stays neutral with regard to jurisdictional claims in published maps and institutional affiliations.

Copyright: (c) 2020 by the authors. Licensee MDPI, Basel, Switzerland. This article is an open access article distributed under the terms and conditions of the Creative Commons Attribution (CC BY) license (https: / / creativecommons.org/ licenses/by/4.0/).

\begin{abstract}
Polyimide (PI) is one of the most excellent polymers for coating. However, the high friction coefficient and the high wear rate of pure PI limit its further applications. In this work, the hollow inorganic fullerene-like $\mathrm{MoS}_{2}$ / reduced graphene oxide (HIF-MoS $/ \mathrm{r}-\mathrm{GO}$ ) nanocomposite filled PI coating is prepared by in situ polymerization. Reinforcement in mechanical strength and thermal stability is realized on the PI composite coating with incorporation of HIF-MoS $2 / r-G O$, which performs better than carbon nanofiber (CNF). Reduced elastic modulus and hardness of HIF$\mathrm{MoS}_{2} / \mathrm{r}-\mathrm{GO} / \mathrm{PI}$ coating is increased by $8.3 \%$ and $4.8 \%$, respectively. The addition of HIF-MoS $2 / \mathrm{r}-\mathrm{GO}$ also results in $24 \%$ higher residual mass at $800{ }^{\circ} \mathrm{C}$ than CNF. Tribological study indicates that, HIF$\mathrm{MoS}_{2} / \mathrm{r}-\mathrm{GO} / \mathrm{PI}$ achieves a wear rate reduction of $79 \%$ compared with pure PI under dry sliding condition, which is much more effective than other nanofillers including CNF, r-GO nanosheets and $\mathrm{MoS}_{2}$ nanoparticles. Under ionic liquid-lubricated condition, the presence of $\mathrm{HIF}-\mathrm{MoS}_{2} / \mathrm{r}-\mathrm{GO}$ in PI results in a $30 \%$ reduction in wear rate and $10 \%$ reduction in friction coefficient as compared to pure PI. It is thought that the HIF-MoS 2 /r-GO in PI can be slowly released to the frictional interface and form a protective film during sliding, in this way the aggregation problem is successfully solved.
\end{abstract}

Keywords: nanocomposite coating; structure; reinforcement; friction and wear; graphene; inorganic fullerene-like $\mathrm{MoS}_{2}$

\section{Introduction}

Polymers are very promising candidates in a wide range of tribological applications for their excellent mechanical strength, low friction, high chemical stability, light weight, etc. [1-4]. They can not only be used as substitutes for traditional materials, but also as coatings on these materials to improve their lifetime and widen their service conditions [5-7]. Polyimide (PI) is one of the most excellent polymers for coating due to its outstanding thermostability, mechanical properties and chemical stability, especially in severe service conditions [8]. However, the high friction coefficient and the high wear rate of pure PI limit its further applications. In view of this point, great efforts have been made to reinforce PI using functional nanofillers, e.g., $\mathrm{SiO}_{2}, \mathrm{ZnO}$, carbon nanotube and graphene [9-12]. The enhancing mechanisms on tribological properties of nanofillers/polymer coatings mainly include higher strength and creep resistance, the formation of stable transfer film giving low friction coefficient, and the micro-rolling/sliding effect of nanoparticles [13-15].

In recent years, graphene and $\mathrm{MoS}_{2}$-based materials have proven to be very effective additives in polymers. Graphene and their derivatives can realize the high strength as well as high tribological properties in very low content $[8,16,17] . \mathrm{MoS}_{2}$ is one of the most prominent lubricating fillers with ultra-high load-carrying capability and excellent frictionreducing performance. Until now, $\mathrm{MoS}_{2}$ in various sizes and morphologies have been 
extensively studied as fillers in polymers [18,19]. It is widely recognized that the family of two-dimensional (2D) nanomaterials can enter the frictional interface and reduce direct contact between the polymer and counterpart. Yuan et al. [19] prepared the 2D $\mathrm{MoS}_{2}$ nanosheets by a high shear mixing technique and filled them into polyamic acid (PAA) precursors to get the $\mathrm{MoS}_{2}$ /PI nanocomposite film. The reported $\mathrm{MoS}_{2} / \mathrm{PI}$ film showed significantly enhanced mechanical and thermal properties.

In addition, the properties of polymer composite coatings are greatly affected by the nanofiller's shape and the way it is assembled [14]. Due to the high dispersion and special microstructure, nanocomposite can remarkably improve the mechanical and tribological properties of polymers. Yuan et al. [20] reported a facile and efficient approach to overcome the poor dispersion of $\mathrm{MoS}_{2}$ nanoflowers in PI by carefully grafting them onto the surface of hollow carbon nanofibers (HCNF). It revealed that tribological properties of PI composite coatings were effectively improved under different lubrication conditions after incorporating small amounts of $\mathrm{MoS}_{2} / \mathrm{HCNF}$. Xin et al. [11,21] prepared the multi-dimensionally assembled nanocomposites of modified graphene/carbon nanotube (CNT) and $\mathrm{MoS}_{2} / \mathrm{CNT}$ by chemical interaction; both of them greatly increased the mechanical strength and tribological properties of PI-based coatings. These works indicate that, as multidimensional nanohybrids, the geometric microstructure has a crucial influence on achieving optimal performance. Also based on the impact of structure, we recently synthesized a novel hollow fullerene-like $\mathrm{MoS}_{2}$ /reduced graphene oxide (HIF-MoS $/$ r-GO) nanocomposite by

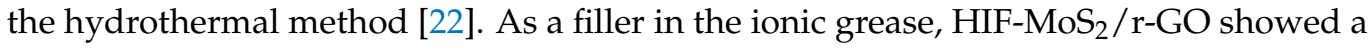
great advantage in lubricating properties over other additives including $\mathrm{MoS}_{2}$ nanoparticles, and single and physically mixed forms of r-GO or HIF-MoS 2 . The application of HIF-MoS $/$ r-GO nanocomposite should be far beyond this. In consideration of the sliding/rolling of spherical HIF-MoS 2 at the interface [23], it is very likely that HIF-MoS $2 /$ r-GO will be an excellent additive in polymer composite coatings.

From another point of view, the wear rate and friction coefficient of polymers can be remarkably reduced with liquid lubrication [24-27]. Moreover, adding fillers in either polymers or lubricants can further enhance tribological properties of the lubricated polymers. The work by Zhao et al. [28] showed that the addition of short glass fibers (SGF) and $\mathrm{ZnS}$ particles into PI led to a synergetic role in friction reduction. Additionally, under low sliding speeds with the limited hydrodynamic effect of oil film, ZnS/SGF/PI exhibited enhanced wear resistance in comparison to the composite reinforced only with SGF. In our previous work, graphene oxide (GO) was added to polyetheretherketone (PEEK) or water to improve the tribological properties of water-lubricated PEEK-steel [29]. Results indicated that in comparison with adding GO into PEEK, adding GO into water exhibits much better friction-reducing and anti-wear properties. However, different from adding fillers into the polymers, it is normally difficult to get the well dispersed lubricants containing inorganic nanoparticles such as graphene and $\mathrm{MoS}_{2}$. Surface functionalization with surfactant-like substances has been widely studied to improve the dispersity, but the modified nanoparticles are prone to degradation under tribological conditions leading to unstable lubricating properties [30].

In this work, the HIF-MoS 2 /r-GO filled PI coating was prepared by in situ polymerization. The mechanical properties, thermal stability and tribological properties of the coatings were studied. Carbon nanofiber (CNF), which has proven to be as an effective additive for polymers [31,32], was studied for comparison. Additionally, the commercial $\mathrm{MoS}_{2}$ nanoparticles and pure r-GO were filled into the PI coating respectively for tribological tests. Furthermore, ionic liquid (IL) was used as a liquid lubricant to study the effect of $\mathrm{HIF-MoS} / \mathrm{r}-\mathrm{GO}$ in PI under the lubricated condition. It was expected to achieve a synergistic effect on the PI coating by using liquid lubricant and incorporating $\mathrm{HIF}-\mathrm{MoS}_{2} / \mathrm{r}-\mathrm{GO}$ nanocomposite. 


\section{Materials and Methods}

\subsection{Materials}

Bisphenol-A dianhydride (BPADA, 99\% purity, Shandong XiYa Chemical Industry Co., Ltd., Jinan, China), 4,4'-oxydianiline (ODA, 98\% purity, Meryer (Shanghai, China) Chemical Technology Co., Ltd., Shanghai, China), and N,N-Dimethylformamide (DMF, 99.5\% purity, Sinopharm Chemical Reagent Co., Ltd., Shanghai, China) were used as received. CNF was purchased from Beijing Deke Island Gold Technology Co., Ltd., Beijing, China. Ionic liquid of 1-ethyl-3-methylimidazolium bis(trifluoromethyl sulfonyl)imide ([Emim][NTf $\left.{ }_{2}\right], 99 \%$ purity) was supplied by Linzhou Keneng Materials Technology Go., Ltd., Anyang, China.

\subsection{Preparation of Additives and PI Composite Coatings}

HIF-MoS 2 /r-GO nanocomposite was synthesized by the hydrothermal method; the detailed process was included in our previous work [22]. GO was synthesized by the improved Hummers' method described in the previous paper [33]. r-GO was fabricated by thermally reducing GO. The thermal reduction condition was the same as that in HIF$\mathrm{MoS}_{2} / \mathrm{r}$-GO synthesis, that is, GO was heated to $800^{\circ} \mathrm{C}$ at $5^{\circ} \mathrm{C} / \mathrm{min}$ under Ar flowing for $2 \mathrm{~h}$.

The PI composite coatings were prepared on polished 1045 steel substrates, and the preparation included in situ polymerization, tape casting and thermal imidization processes. In a typical operation to prepare the $\mathrm{HIF}_{-} \mathrm{MoS}_{2} / \mathrm{r}-\mathrm{GO}$ filled PI coating, ODA $(2.503 \mathrm{~g}, 12.5 \mathrm{mmol})$ was added into a $50 \mathrm{~mL}$ two-necked flask containing $38 \mathrm{~mL}$ DMF with aid of sonication for $10 \mathrm{~min}$, then the as-prepared $\mathrm{HIF}-\mathrm{MoS}_{2} / \mathrm{r}-\mathrm{GO}$ at different loadings (i.e., $0.5 \%, 1.0 \%, 1.5 \%$ and $2 \%$ by weight) were added into the above solutions and dispersed by sonication until the nanocomposites were dispersed homogeneously in the mixed solution. BPADA $(6.506 \mathrm{~g}, 12.5 \mathrm{mmol})$ was gradually added into above mixed solution, and the mixture was stirred at room temperature for $24 \mathrm{~h}$ under nitrogen. Finally, the $\mathrm{HIF-MoS} / \mathrm{r}-\mathrm{GO} /$ polyamic acid (PAA) solutions were obtained via in situ polymerization. The as-formed HIF-MoS 2 /r-GO/PAA solutions were dropped onto polished steel blocks. Subsequently, the mixtures were dried in a vacuum oven at $80^{\circ} \mathrm{C}$ for $10 \mathrm{~h}$ by evaporating solvent. The thermal imidization process was performed in a muffle furnace at $70{ }^{\circ} \mathrm{C}$ for $2 \mathrm{~h}$, and at 100,150, 200 and $300^{\circ} \mathrm{C}$ for $1 \mathrm{~h}$. The other coatings were also prepared by the above-mentioned method. The coating thickness was around $50 \mu \mathrm{m}$.

\subsection{Characterization of Coatings}

The morphology and composition of the HIF-MoS 2 / r-GO nanocomposite were studied in our previous work, using high-resolution transmission electron microscopy (TEM) with an energy dispersive X-ray spectroscopic (EDX) detector, Raman spectroscopy, and a powder Xray diffractometer (PXRD) [22]. To check the distribution of fillers in PI composite coatings, the coatings were fractured to examine the microscopic cross section with a scanning electron microscopy (SEM, Hitachi S-4800, Tokyo, Japan). The coatings for cross section study and thermogravimetric analysis (TGA) were prepared on silica glass in convenience to be peeled off. TGA was performed by the Discovery SDT 650 analyser (TA Instruments, Inc., New Castle, DE, USA) from 30 to $850{ }^{\circ} \mathrm{C}$ in a nitrogen $\left(\mathrm{N}_{2}\right)$ atmosphere at a heating rate of $10{ }^{\circ} \mathrm{C} / \mathrm{min}$. Three repeated TGA tests were done to minimize the error range. Mechanical properties of PI-based coatings were evaluated by a nanoindenter (Agilent G200, Santa Clara, CA, USA) with following parameters: peak/maximum indentation load of $30 \mathrm{mN}$ with a loading and unloading rate of $0.05 \mathrm{mN} / \mathrm{s}$, and a holding time of $50 \mathrm{~s}$ at the peak loads. The mean values of hardness $(H)$ and reduced elastic modulus $\left(E_{\mathrm{r}}\right)$ were obtained by averaging at least three different surface positions for each sample.

\subsection{Tribological Tests}

A multifunctional material surface performance tester (model CFT-I, Lanzhou Zhongke Kaihua Technology Development Co., Lanzhou, China) operated by ball-on-disc mode 
was used to evaluate the friction and wear behaviours of PI-based coatings. Commercially available 100Cr6 steel ball (diameter $6 \mathrm{~mm}$, surface roughness $\mathrm{Ra} \leq 30 \mathrm{~nm}$ ) was used as the stationary upper counterpart, while the PI-based coatings were mounted onto the flat base. The flat base was driven to reciprocally move at a frequency of $10 \mathrm{~Hz}$ with a stroke length of $5 \mathrm{~mm}$. For tribological properties under dry sliding condition, tests were conducted at room temperature of $25 \pm 5{ }^{\circ} \mathrm{C}$, elevated temperatures of 100 and $250{ }^{\circ} \mathrm{C}$, and the relative humidity was $50 \pm 5 \%$. The applied loads were 2 and $6 \mathrm{~N}$ for the room temperature test and $6 \mathrm{~N}$ for the high temperature test; the testing duration was $30 \mathrm{~min}$. For tribological properties under the lubricated condition, [Emim][ $\left.\mathrm{NTf}_{2}\right]$ was dropped on the coatings, forming an IL-lubricated condition. Due to the negligible wear at 2 and $6 \mathrm{~N}$ under the IL-lubricated condition, the applied load was increased to $20 \mathrm{~N}$ to evaluate the tribological properties.

The friction coefficient-versus-time curve was recorded automatically with a data acquiring system linked to the tester. Wear volume $(V)$ of the coatings was tested by scanning the wear scars and accumulating the volume loss. The specific wear rate $K$ $\left(\mathrm{mm}^{3} /(\mathrm{N} \cdot \mathrm{m})\right)$ was calculated by Equation $(1)$.

$$
K=V F^{-1} L^{-1}
$$

where $F$ and $L$ are the normal load and sliding distance of the wear test, respectively. At least three repeated measurements were performed for each frictional pair. The worn surface of coatings generated from PI, CNF/PI and HIF-MoS $/$ r-GO/PI under dry sliding condition was studied using an optical microscope (Model MV6100, Nanjing Jiangnan Novel Optics Co., Ltd., Nanjing, China) and SEM.

\section{Results and Discussion}

\subsection{Mechanical and Thermal Properties}

Figure 1 shows the SEM images of the fractured surface for different PI coatings. Inserts in Figure 1b,c are the as-prepared HIF-MoS $2 / r-G O$ and as-received CNF, respectively. Pure PI coating has a smooth fractured surface (Figure 1a), and the CNF-reinforced coating also shows a smooth surface with incorporated CNF (Figure 1c). On the contrary, $\mathrm{HIF}-\mathrm{MoS}_{2} / \mathrm{r}-\mathrm{GO} / \mathrm{PI}$ has an irregular fractured surface where the added HIF-MoS $/ \mathrm{r}-\mathrm{GO}$ can be observed (Figure 1b). On the one hand, it reveals that the added HIF-MoS $/ \mathrm{r}-\mathrm{GO}$ nanocomposite is well dispersed in PI. On the other hand, the ball-on-plate structure of HIF-MoS 2 /r-GO may help form a robust barrier throughout the nanocomposite coating.
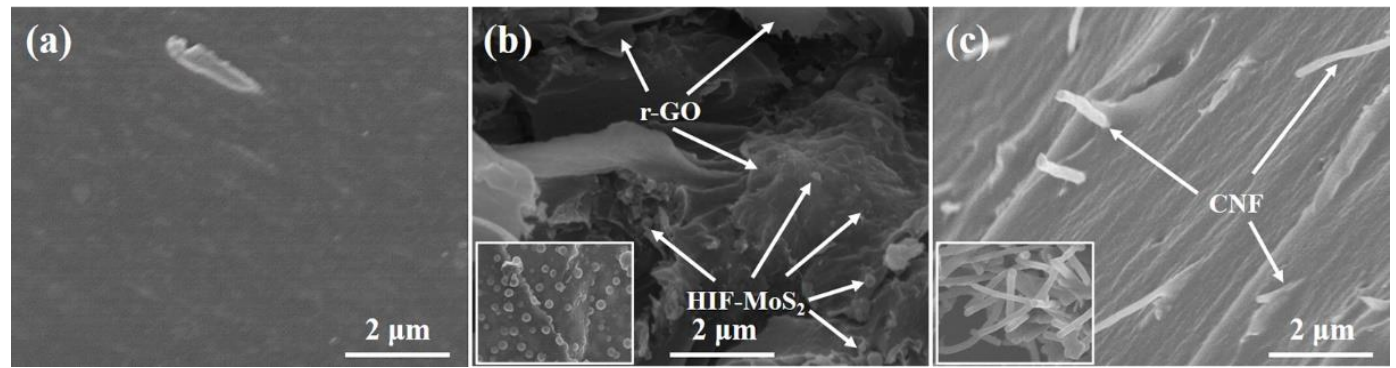

Figure 1. Scanning electron microscopy (SEM) images of fractured surface for different polyimide (PI) composite coatings: (a) PI, (b) $1.5 \% \mathrm{HIF}-\mathrm{MoS}_{2} / \mathrm{r}-\mathrm{GO} / \mathrm{PI}$ and (c) $1.5 \% \mathrm{CNF} / \mathrm{PI}$. Inserts in (b) and (c) are the HIF-MoS $2 / \mathrm{r}-\mathrm{GO}$ and carbon nanofiber (CNF) at the same magnification, respectively. 1.5\%HIF-MoS $2 / \mathrm{r}-\mathrm{GO} / \mathrm{PI}=$ hollow inorganic fullerene-like $\mathrm{MoS}_{2} / \mathrm{reduced}$ graphene oxide.

The reduced elastic modulus $\left(E_{\mathrm{r}}\right)$ and hardness $(H)$ of different PI coatings are compared in Figures 2a,b, respectively. It is found that both $E_{\mathrm{r}}$ and $H$ are improved after the addition of $\mathrm{HIF}-\mathrm{MoS}_{2} / \mathrm{r}-\mathrm{GO}$ and CNF. $E_{\mathrm{r}}$ and $H$ of pure PI is 3.97 GPa and $0.165 \mathrm{GPa}$. As the content of HIF-MoS $2 / \mathrm{r}-\mathrm{GO}$ reaches $1.5 \%$, the $E_{\mathrm{r}}$ and $H$ of $\mathrm{HIF}-\mathrm{MoS}_{2} / \mathrm{r}-\mathrm{GO} / \mathrm{PI}$ is increased to $4.30 \mathrm{GPa}$ and $0.173 \mathrm{GPa}$, with increasing rates of $8.3 \%$ and $4.8 \%$, respectively. While 
the presence of $1.5 \% \mathrm{CNF}$ increases $E_{\mathrm{r}}$ and $H$ by $7.3 \%$ and $4.2 \%$. It is noteworthy that the $2 \% \mathrm{HIF}-\mathrm{MoS}_{2} / \mathrm{r}-\mathrm{GO} / \mathrm{PI}$ and $2 \% \mathrm{CNF} / \mathrm{PI}$ coatings show rough surface with some cracks and holes on the surface, which should be caused by the too high loading of HIF-MoS $2 / \mathrm{r}-\mathrm{GO}$. As the content of nanofillers is more than $1.5 \%$, the viscosity of solution obviously increases, which affects the coating preparation. Moreover, the nanofillers would even aggregate and lead to the poor dispersion. Because of this, the mechanical properties of them were not studied by nanoindenter.
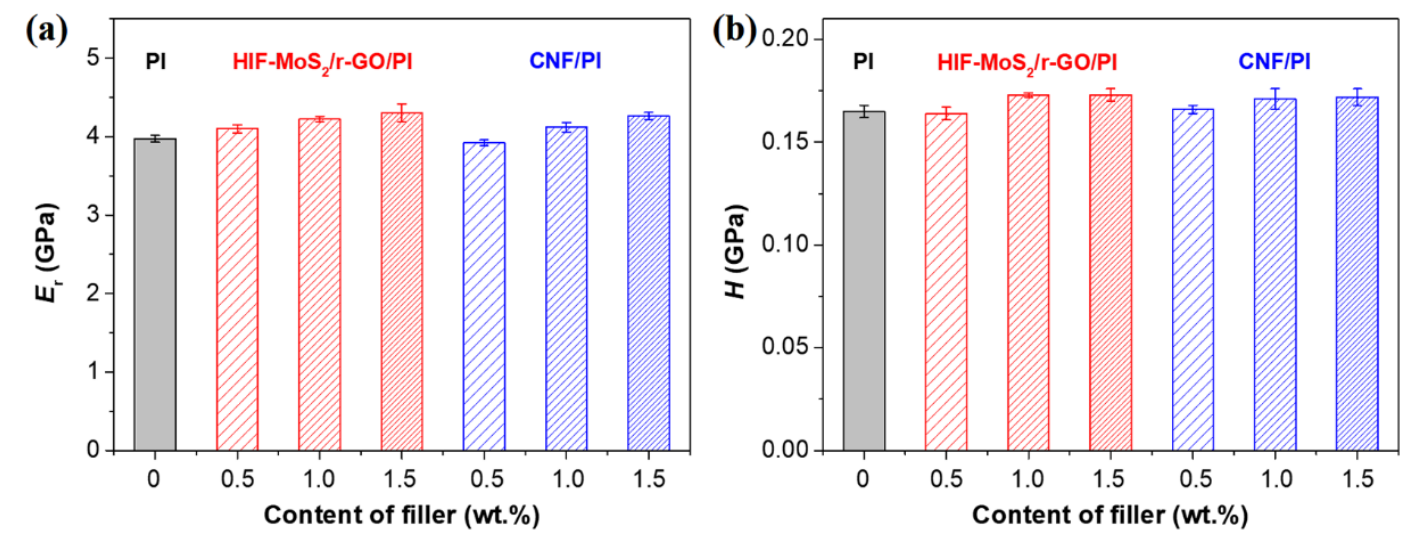

Figure 2. (a) The reduced elastic modulus $\left(E_{\mathrm{r}}\right)$ and $(\mathbf{b})$ the hardness $(H)$ of different PI composite coatings.

TGA was carried out to investigate the influence of nanofillers on thermal stability. Although the TGA study does not directly examine the filler influence on the performance of PI nanocomposite at its working temperature, it may shed light on the micro interaction between the fillers and PI, which would affect the PI nanocomposite's performance. Based on the thermogravimetric (TG) curves shown in Figure 3, the decomposition temperature, the temperature at $5 \%$ and $10 \%$ weight loss, and the residual amount at $800{ }^{\circ} \mathrm{C}$ are obtained. The mean value and standard deviation are listed in Table 1 . The results indicate that HIF$\mathrm{MoS}_{2} / \mathrm{r}-\mathrm{GO}$ and CNF can improve the thermal stability of PI coating, with the optimum loading of $1.5 \%$. The residual amount at $800{ }^{\circ} \mathrm{C}$ for pure PI and $1.5 \% \mathrm{HIF}_{-} \mathrm{MoS}_{2} / \mathrm{r}-\mathrm{GO} / \mathrm{PI}$ is $47.5 \%$ and $65.0 \%$, respectively. The residual amount for $1.5 \% \mathrm{HIF}-\mathrm{MoS}_{2} / \mathrm{r}-\mathrm{GO} / \mathrm{PI}$ is $37 \%$ higher than pure PI. 2.0\%HIF-MoS $/ \mathrm{r}-\mathrm{GO} / \mathrm{PI}$ shows relatively lower thermal properties than $1.5 \% \mathrm{HIF}_{-} \mathrm{MoS}_{2} / \mathrm{r}-\mathrm{GO} / \mathrm{PI}$, which should be induced by the defects in the PI composite with too high loading of HIF-MoS $/$ r-GO. The thermal stability of HIF-MoS $/$ r-GO/PI is higher than that of CNF/PI. The addition of $1.5 \% \mathrm{HIF}-\mathrm{MoS}_{2} / \mathrm{r}-\mathrm{GO}$ results in $24 \%$ higher residual amount at $800{ }^{\circ} \mathrm{C}$ than that of $1.5 \% \mathrm{CNF}$. The higher stability of $\mathrm{HIF}-\mathrm{MoS}_{2} / \mathrm{r}-\mathrm{GO} / \mathrm{PI}$ is thought to be ascribed to improvement of the physical barrier effect by HIF-MoS $2 / r-G O$ as compared to CNF, which could delay the thermal degradation of PI [34]. During thermal degradation, small molecules will emit from the heated samples. Due to the barrier effect by highly thermal stable 2D fillers, the emission can be inhibited, and the thermal degradation will be delayed. Since CNF is in fibre shape, it provides very limited area to protect PI. It is worth mentioning that the PI composite should have higher thermal properties than the mixture obtained via physical mixing the components, because the PAA precursor is in situ polymerized on the surface of nanocomposite and the produced PI highly adheres to the surface. It can be revealed from the result that very low content of fillers ( $\leq 2 \mathrm{wt} . \%)$ in PI composites induces a big difference in the residual amount. The higher thermal properties of $\mathrm{HIF}-\mathrm{MoS}_{2} / \mathrm{r}-\mathrm{GO} / \mathrm{PI}$ also suggest that after adding the HIF-MoS 2 /r-GO nanocomposite, a robust protective barrier could be formed within the nanocomposite coating. 

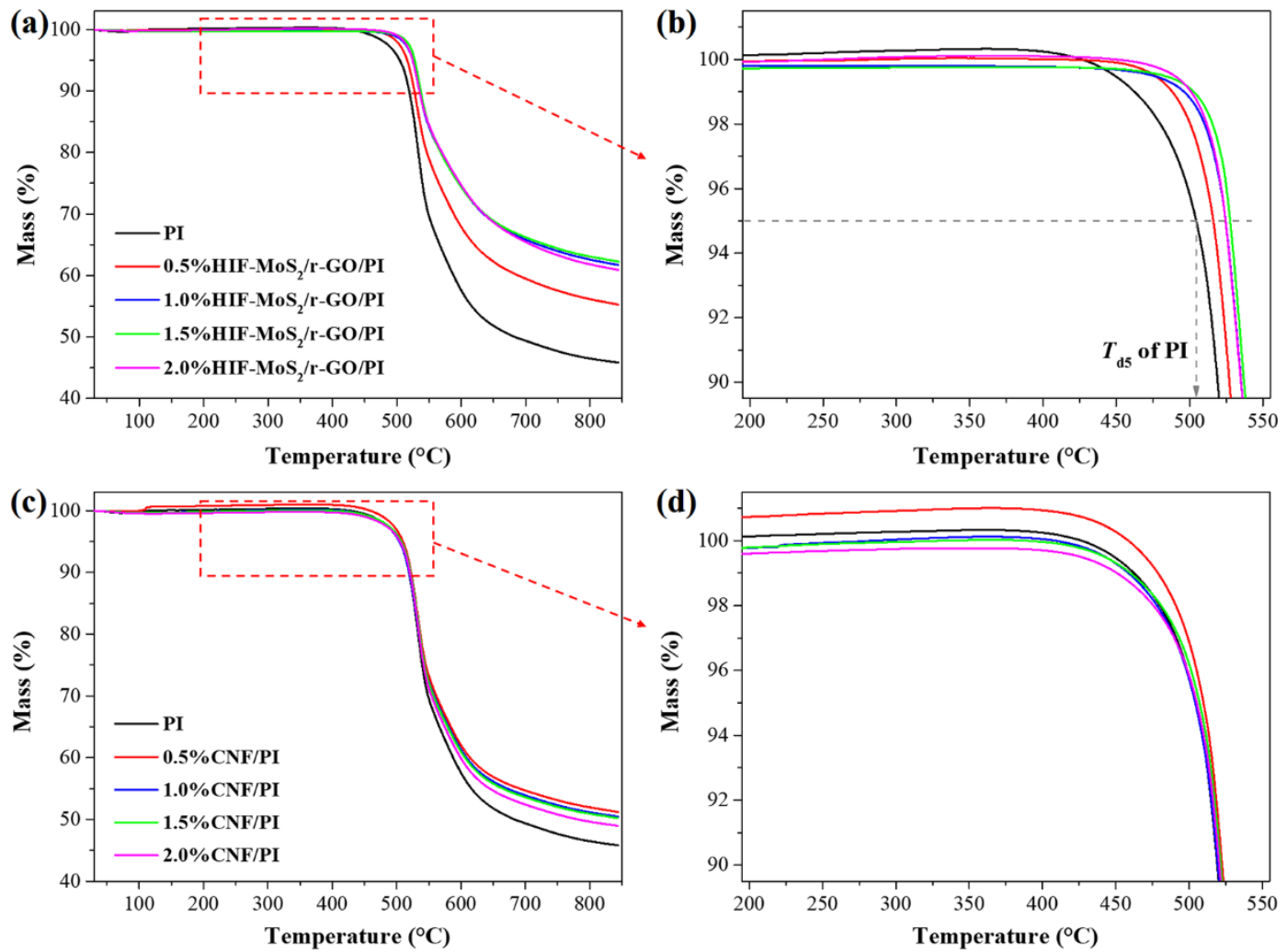

Figure 3. Typical thermogravimetric (TG) curves of PI composites in nitrogen $\left(\mathrm{N}_{2}\right)$ atmosphere: $(\mathbf{a}, \mathbf{b}) \mathrm{HIF-MoS_{2 } / r - G O / P I}$ and (c,d) CNF/PI, with the curve of pure PI for comparison.

Table 1. Thermal analysis of different PI composite coatings.

\begin{tabular}{ccccc}
\hline PI Coatings & $\left.\boldsymbol{T}_{\text {onset }}{ }^{(\mathbf{a})} \mathbf{(}{ }^{\circ} \mathbf{C}\right)$ & $\mathbf{T d}_{\mathbf{5}}{ }^{(\mathbf{b})}\left({ }^{\circ} \mathbf{C}\right)$ & $\mathbf{T d}_{\mathbf{1 0}}{ }^{(\mathbf{c})}\left({ }^{\circ} \mathbf{C}\right)$ & Residual Amount at 800 ${ }^{\circ} \mathbf{C}(\%)$ \\
\hline PI & $506.6 \pm 2.2$ & $505.6 \pm 1.8$ & $520.4 \pm 1.5$ & $47.5 \pm 1.6$ \\
0.5\%HIF-MoS $/$ r-GO/PI & $510.0 \pm 0.4$ & $516.7 \pm 1.8$ & $528.0 \pm 1.5$ & $58.6 \pm 2.0$ \\
1.0\%HIF-MoS $/$ r-GO/PI & $515.6 \pm 0.3$ & $524.9 \pm 0.5$ & $535.7 \pm 0.8$ & $63.5 \pm 0.8$ \\
1.5\%HIF-MoS $/$ r-GO/PI & $519.3 \pm 0.5$ & $527.2 \pm 1.1$ & $536.7 \pm 1.2$ & $65.0 \pm 2.1$ \\
2.0\%HIF-MoS $/$ r-GO/PI & $514.1 \pm 0.4$ & $524.0 \pm 0.7$ & $534.7 \pm 0.4$ & $61.0 \pm 1.2$ \\
0.5\%CNF/PI & $506.5 \pm 1.9$ & $507.7 \pm 1.9$ & $520.6 \pm 1.7$ & $51.8 \pm 0.2$ \\
1.0\%CNF/PI & $506.3 \pm 0.7$ & $507.3 \pm 0.6$ & $519.7 \pm 0.7$ & $51.8 \pm 1.4$ \\
1.5\%CNF/PI & $508.2 \pm 2.0$ & $508.1 \pm 1.3$ & $521.4 \pm 0.3$ & $52.0 \pm 1.5$ \\
2.0\%CNF/PI & $508.0 \pm 1.5$ & $507.2 \pm 2.0$ & $521.0 \pm 0.6$ & $49.7 \pm 1.4$ \\
\hline
\end{tabular}

Note: ${ }^{(a)}$ Initial decomposition temperature; ${ }^{(b)}$ Temperature at $5 \%$ weight loss; ${ }^{(c)}$ Temperature at $10 \%$ weight loss.

\subsection{Tribological Properties}

\subsubsection{Under Dry Sliding Condition}

Tribological properties of different PI composite coatings at dry sliding condition and room temperature are compared in Figure 4. As shown in Figure $4 \mathrm{a}$, the friction coefficient of pure PI is 0.492 . After adding $1 \% \mathrm{HIF}-\mathrm{MoS}_{2} / \mathrm{r}-\mathrm{GO}$, the friction coefficient is reduced to 0.431 , with a reduction of $12 \%$. While CNF can maximally reduce the friction coefficient by just $6 \%$ at $0.5 \%$ loading. Higher CNF even leads to an increase in friction coefficient as compared to pure PI. The anti-wear property of PI composite coating is remarkably improved with HIF-MoS 2 r-GO (Figure $4 \mathrm{~b}$ ). At the optimum loading of $1.5 \%$, the wear rate can be reduced by $79 \%$, which is much better than the other fillers at their optimum content. It is noteworthy that the improvement by adding HIF-MoS $2 / r-G O$ is much greater than just adding r-GO or $\mathrm{MoS}_{2}$ nanoparticles. 

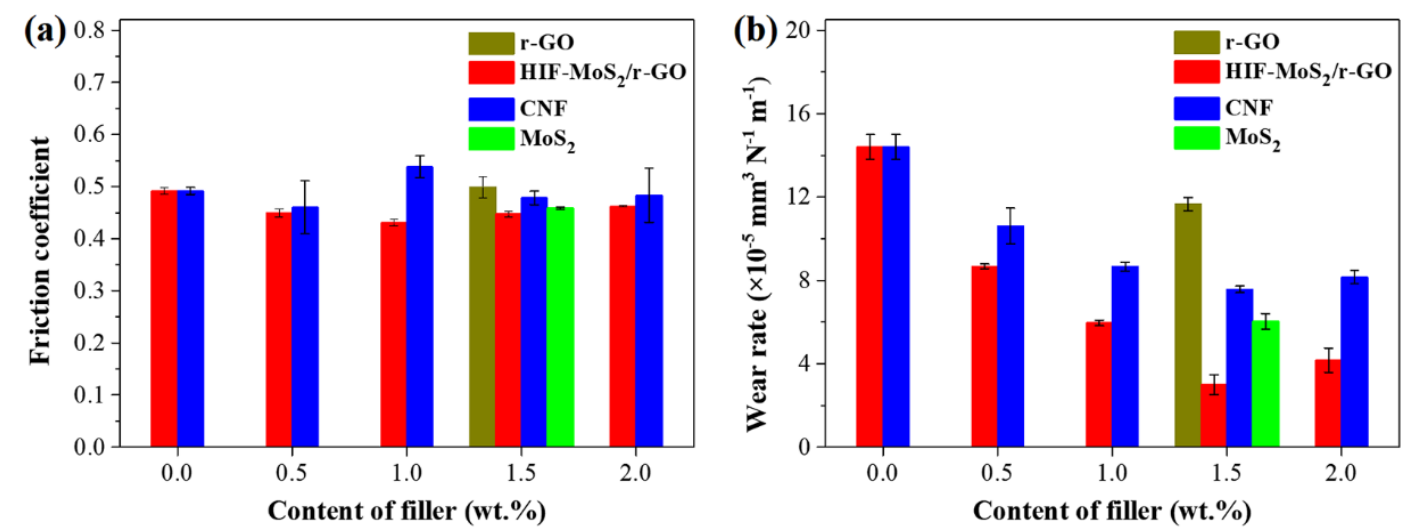

Figure 4. The effect of filler type and content on (a) friction coefficient and (b) wear rate of PI composite coatings under dry sliding condition at room temperature (Load: $2 \mathrm{~N}$ ).

The reinforcing effect of HIF-MoS $/ 2$ r-GO and CNF at their optimum loading, i.e., $1.5 \%$, was further examined under a higher load of $6 \mathrm{~N}$ at room temperature. Pure PI and 1.5\%CNF/PI both show increased friction coefficient over time, while 1.5\%HIF$\mathrm{MoS}_{2} / \mathrm{r}-\mathrm{GO} / \mathrm{PI}$ shows lower and stable friction coefficient throughout the test run (Figure 5). The main reason for the increased friction coefficient is thought to be the increased contact surface for the poor anti-wear property. Pure PI is even worn out and the steel surface is exposed (Figure $6 \mathrm{a}, \mathrm{d}$ ). $1.5 \% \mathrm{CNF} / \mathrm{PI}$ shows improved anti-wear performance with a wear depth of $25 \mu \mathrm{m}$ (Figure $6 \mathrm{f}$ ). By filling $1.5 \% \mathrm{HIF}-\mathrm{MoS}_{2} / \mathrm{r}-\mathrm{GO}$, the wear depth is just around

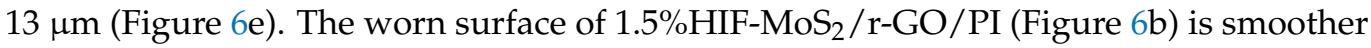
compared to pure PI (Figure 6a) and 1.5\%CNF/PI (Figure 6c). Under higher load, the added HIF-MoS $2 / \mathrm{r}-\mathrm{GO}$ is still able to strengthen the anti-wear transfer film and improve the tribological properties of PI.

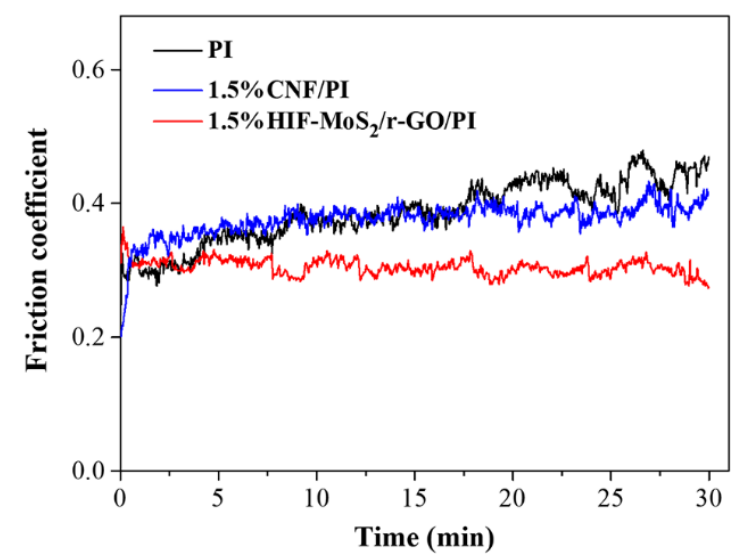

Figure 5. The effect of different fillers on friction coefficient of PI composite coatings under dry sliding condition at room temperature (Load: $6 \mathrm{~N}$ ). 

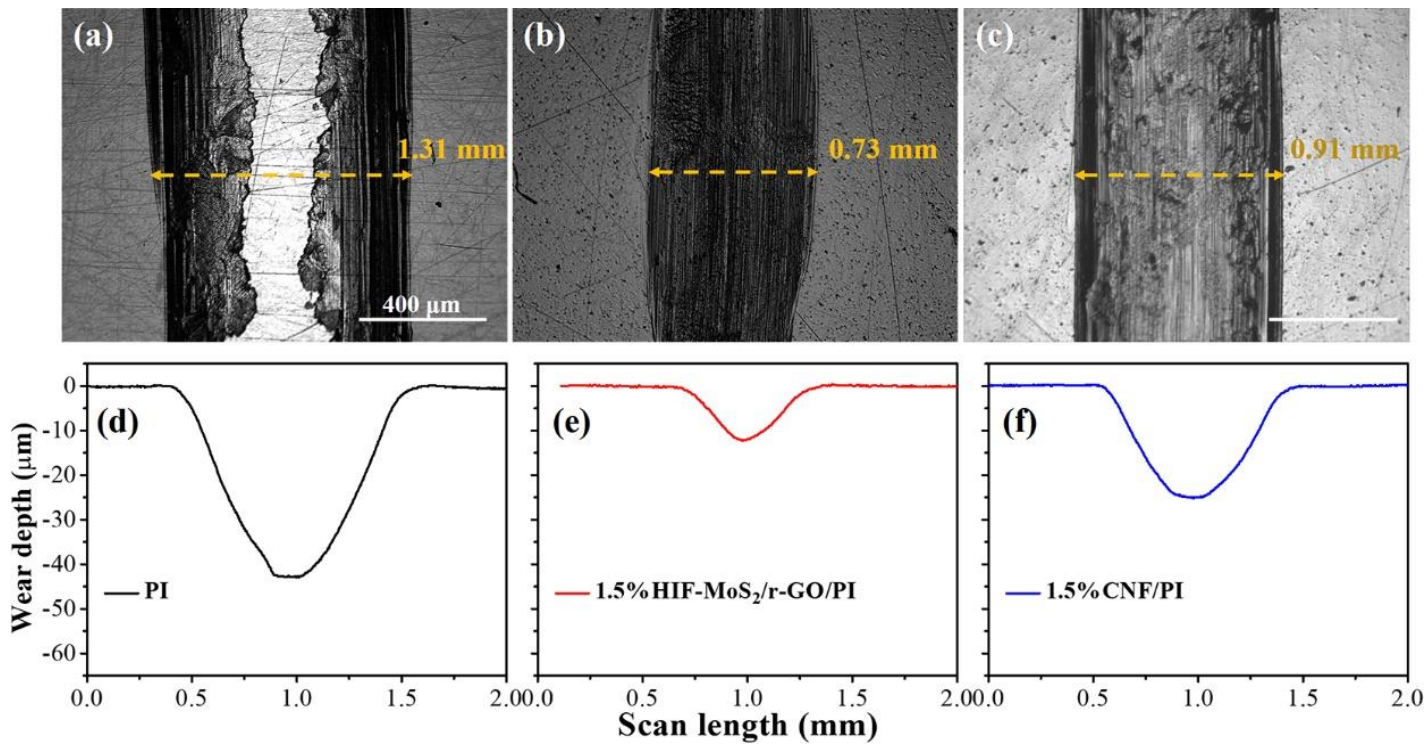

Figure 6. Optical micrographs of worn surfaces of PI coatings with different fillers under dry sliding condition at room temperature: (a) PI, (b) $1.5 \% \mathrm{HIF}_{-} \mathrm{MoS}_{2} / \mathrm{r}-\mathrm{GO} / \mathrm{PI}$, (c) $1.5 \% \mathrm{CNF} / \mathrm{PI}$; (d-f) are worn surface profiles corresponded to (a-c) (Load: $6 \mathrm{~N})$.

Tribological properties of $1.5 \% \mathrm{HIF}-\mathrm{MoS}_{2} / \mathrm{r}-\mathrm{GO} / \mathrm{PI}$ were further studied at elevated temperatures of 100 and $250^{\circ} \mathrm{C}$, and the results of wear rate and online friction coefficient are depicted in Figures $7 \mathrm{a}$ and $7 \mathrm{~b}$, respectively. At $100^{\circ} \mathrm{C}$, the wear rates of both pure PI and $1.5 \% \mathrm{HIF}-\mathrm{MoS}_{2} / \mathrm{r}-\mathrm{GO} / \mathrm{PI}$ coatings are much lower than those at room temperature. At high temperature, more serious adhesive wear is induced instead of abrasive wear. The softened PI material is easier to be sheared to form an anti-wear film at the interface. Compared to the pure PI coating, the wear rate of $1.5 \% \mathrm{HIF}-\mathrm{MoS}_{2} / \mathrm{r}-\mathrm{GO} / \mathrm{PI}$ can be reduced by $32 \%$ and $53 \%$ at $100{ }^{\circ} \mathrm{C}$ and $250{ }^{\circ} \mathrm{C}$, respectively. At a higher temperature of $250{ }^{\circ} \mathrm{C}$, the wear rates are much higher than $100{ }^{\circ} \mathrm{C}$, which should be caused by the reduced mechanical properties [35]. Pure PI with too poor strength cannot stand the shearing force, as a result the coating at $250^{\circ} \mathrm{C}$ shows higher wear than $100{ }^{\circ} \mathrm{C}$. The friction coefficient shows an increasing trend as the temperature increases from $100^{\circ} \mathrm{C}$ to $250^{\circ} \mathrm{C}$. It is thought to be induced by the higher adhesion and higher real contact surface.
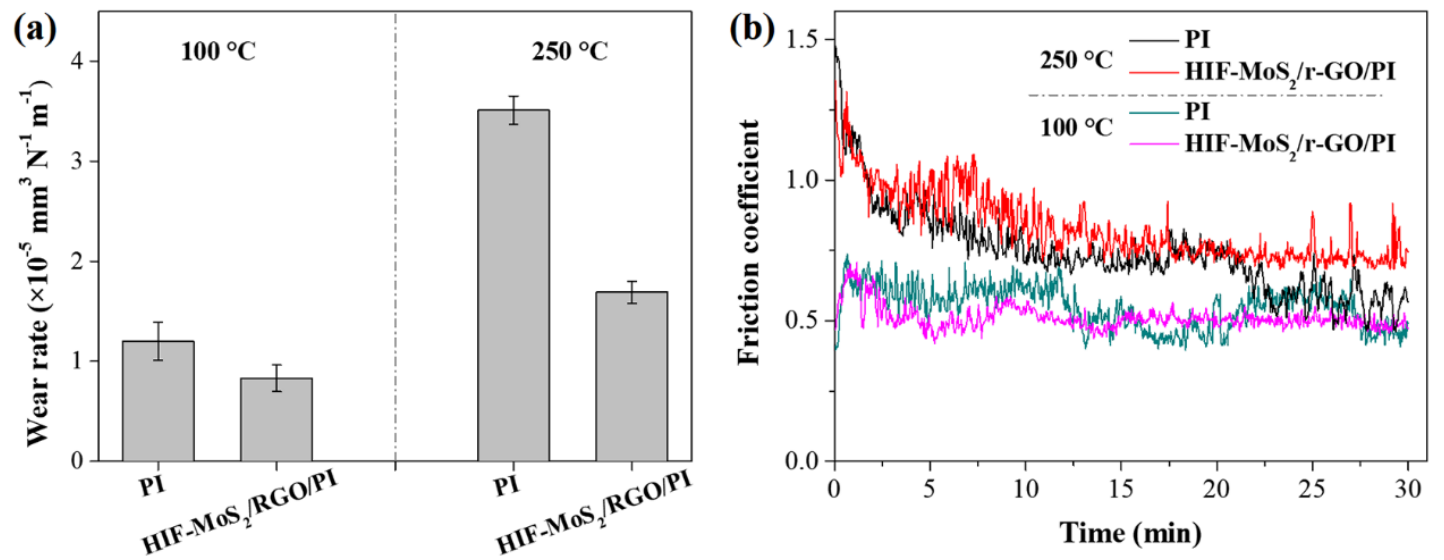

Figure 7. (a) The wear rate and (b) online friction coefficient of pure PI and $1.5 \% \mathrm{HIF}-\mathrm{MoS}_{2} / \mathrm{r}-\mathrm{GO} / \mathrm{PI}$ coatings under dry sliding condition at 100 and $250^{\circ} \mathrm{C}$ (Load: $6 \mathrm{~N}$ ).

To shed light on the mechanism of different tribological properties, the worn surface of the PI-based coatings and wear debris on the steel ball were studied by SEM. Pure PI as 
shown in Figure 8a shows wide and deep furrows along the sliding direction. Figure 8d shows the SEM image of wear debris on the steel ball sliding against pure PI coating. Many stacked wear debris are found with rough edges. These large and thick wear debris indicate that pure PI is easy to wear out, as a result the steel ball slides directly against the fresh $\mathrm{PI}$ and leads to a high wear rate. After filling HIF-MoS $2 / \mathrm{r}-\mathrm{GO}$, the worn surface becomes much smoother with some adhered thin wear debris (Figure $8 b$ ). There is much less wear debris around the worn surface and the steel ball. From the SEM image of Figure 8e, we find that the wear debris of HIF-MoS $/ \mathrm{r}-\mathrm{GO} / \mathrm{PI}$ is relatively thinner and smoother than that of pure PI. In the magnified images, there are small particles of wear debris on the surface for

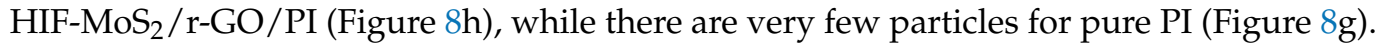
Figure $8 \mathrm{i}$ displays the enlarged region within the rectangular frame, where HIF-MoS nanocages can be found on the surface. The detected HIF-MoS 2 nanocages indicate that they can be released from the HIF-MoS $/ \mathrm{r}-\mathrm{GO}$ nanocomposite during the frictional process. On one hand, the added HIF-MoS $2 /$ r-GO nanocomposite and HIF-MoS ${ }_{2}$ on the surface of $\mathrm{r}-\mathrm{GO}$ can be released to the friction interface to reduce direct contact between steel ball and PI coating. On the other hand, they can in situ repair the worn surface and help form thinner but robust wear debris at the interface to prevent the coating from being further damaged. By filling CNF, the worn surface has deep furrows and microcracks (Figure 8c), and the wear debris as shown in Figure $8 \mathrm{f}$ is similar to that of pure PI coating. The lower tribological properties of CNF/PI compared with HIF-MoS $2 / r-G O / P I$ should be due to the lower ability of CNF to form the transfer film.

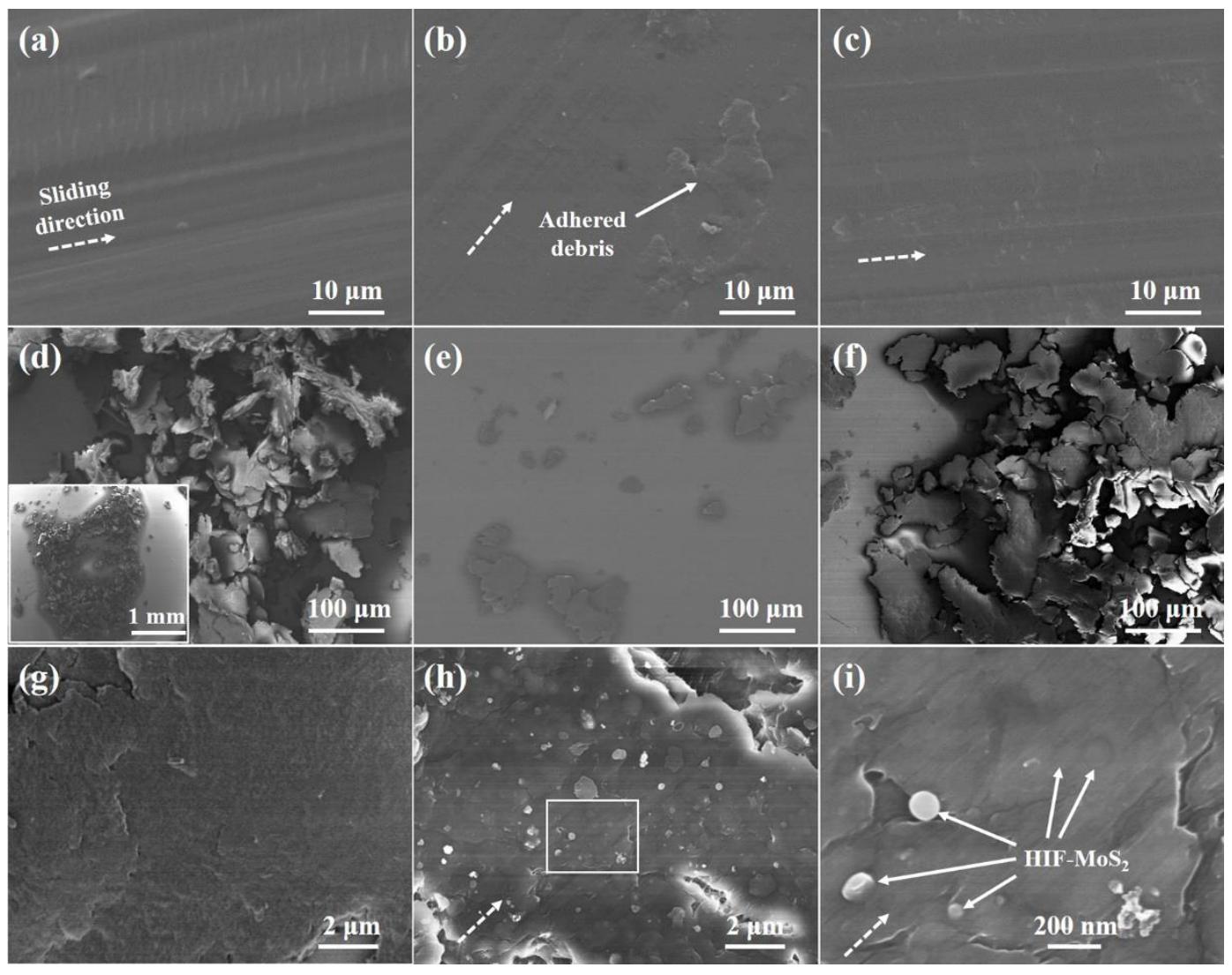

Figure 8. SEM images of $(\mathbf{a}-\mathbf{c})$ worn surfaces and $(\mathbf{d}-\mathbf{i})$ wear debris on the steel ball for different PI coatings under dry sliding condition at room temperature: $(\mathbf{a}, \mathbf{d}) \mathrm{PI},(\mathbf{b}, \mathbf{e}) 1.5 \% \mathrm{HIF}-\mathrm{MoS}_{2} / \mathrm{r}-\mathrm{GO} / \mathrm{PI}$, and (c,f) $1.5 \% \mathrm{CNF} / \mathrm{PI}$. Insert in (d) shows the overall image of wear debris on steel ball sliding against pure PI coating. The magnified SEM images of wear debris for PI and HIF-MoS 2 /r-GO/PI are shown in (g) and (h), respectively, and (i) displays the enlarged region within the white rectangular frame in (h). (Load: $2 \mathrm{~N}$ ). 
The structure of HIF-MoS $/$ r-GO filled PAA precursors is shown in Figure 9a, and the proposed friction and wear mechanism of $\mathrm{HIF}-\mathrm{MoS}_{2} / \mathrm{r}-\mathrm{GO} / \mathrm{PI}$ coating is shown in Figure 9b. Different from the fibrous CNF, the HIF-MoS 2 on r-GO can act as nano balls after being peeled from the r-GO surface (Figure 9b). Additionally, after the breakage of HIF-MoS nanocages, the $\mathrm{MoS}_{2}$ nanosheet debris could also fill the worn surface to form the anti-wear and friction-reducing transfer film. Regarding the r-GO nanosheets, they can not only work as a robust anti-wear additive, but also serve as the storer for HIF-MoS 2 for slow release of HIF-MoS 2 . Aggregation is a common problem in the preparation and performing of nanoparticles filled materials. By assembling HIF-MoS 2 and r-GO, the aggregation problem can be avoided. The nano-sized HIF-MoS 2 dotted on r-GO can avoid the aggregation of r-GO nanosheets. During the preparation of $\mathrm{HIF}-\mathrm{MoS}_{2} / \mathrm{r}-\mathrm{GO} / \mathrm{PI}$ composite coating, the PI can fully adhere to HIF-MoS 2 and r-GO because of the enlarged gaps between HIF$\mathrm{MoS}_{2} / \mathrm{r}$-GO nanocomposites, which can not only enhance the mechanical properties, but also realize the slow release of nanoparticles under shearing force.
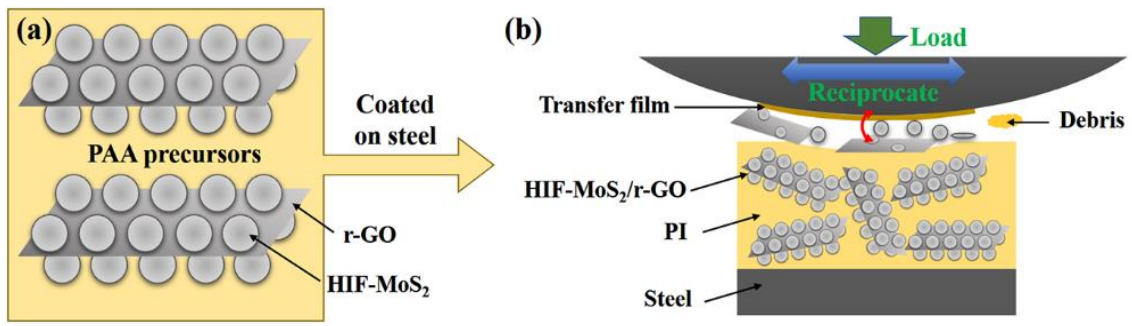

Figure 9. (a) The structure of $\mathrm{HIF-MoS_{2 }} / \mathrm{r}-\mathrm{GO}$ filled PAA precursors, and (b) the proposed friction and wear mechanism of HIF-MoS 2 r-GO/PI under dry sliding condition.

\subsubsection{Under Lubricated Condition}

For the IL-lubricated condition, commercial IL of [Emim][NTf 2$]$ was dropped on the coating as a lubricant. The PI coating shows much lower wear and friction coefficient under IL-lubricated condition as compared to the dry sliding condition (Figure 10). It is exciting that the addition of $\mathrm{HIF}-\mathrm{MoS}_{2} / \mathrm{r}-\mathrm{GO}$ results in a $30 \%$ reduction of wear as compared to pure PI, and the friction coefficient is further reduced by $10 \%$. It is noteworthy that tribological tests were also conducted under low loads of 2 and $6 \mathrm{~N}$, but the wear of coatings was too low to be detected by the machine. Even under $20 \mathrm{~N}$, the wear rate of PI and $\mathrm{HIF}-\mathrm{MoS}_{2} / \mathrm{r}-\mathrm{GO} / \mathrm{PI}$ coating is just $10 \times 10^{-7}$ and $7 \times 10^{-7} \mathrm{~mm}^{3} \mathrm{~N}^{-1} \mathrm{~m}^{-1}$, respectively.

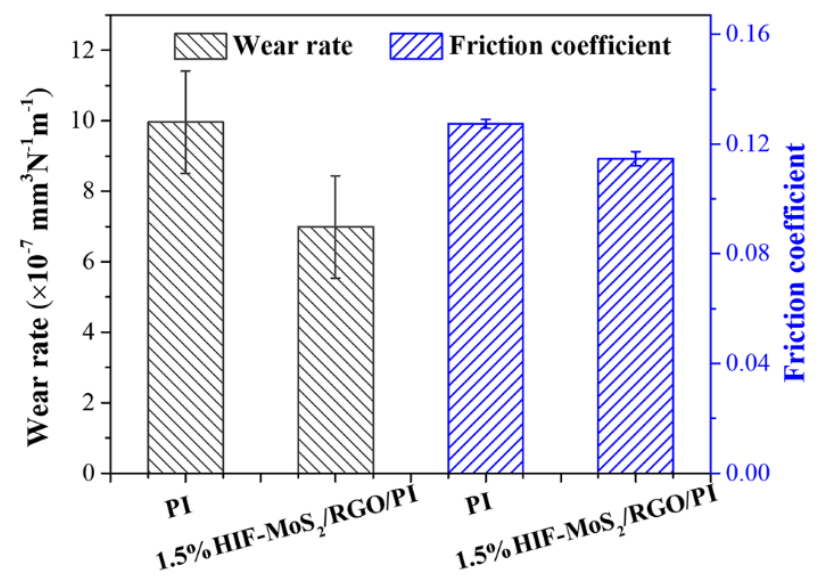

Figure 10. The wear rate and friction coefficient of IL-lubricated PI and $1.5 \% \mathrm{HIF}-\mathrm{MoS} / \mathrm{r}-\mathrm{GO} / \mathrm{PI}$ (Load: $20 \mathrm{~N}$ ).

Under the testing conditions, the IL-lubricated contact is in the mixed regime of elastohydrodynamic lubrication and boundary lubrication. From the mechanical perspective, 
the filled HIF-MoS $2 / r-G O$ enhances the mechanical strength of the PI coating, giving rise to a higher anti-wear property. From the microscale interfacial effect, $\mathrm{HIF}-\mathrm{MoS}_{2} / \mathrm{r}-\mathrm{GO}$ and the deciduous HIF-MoS 2 can be slowly released from the coating to the frictional interface, which can prevent direct contact of the PI coating and the steel ball. The lower friction coefficient indicates that the HIF-MoS $2 / \mathrm{r}-\mathrm{GO}$ in PI can in situ form a protective tribological film during sliding. Due to the ball-on-plate structure of $\mathrm{HIF}-\mathrm{MoS}_{2} / \mathrm{r}-\mathrm{GO}$ nanocomposite, the released HIF-MoS 2 acts as rolling balls which can prevent the contact between the asperities of two sliding surfaces, resulting in a further decrease in the friction coefficient. In case of a severe contact condition where the HIF-MoS 2 could be broken, the thin IF-MoS 2 nanosheets could also reduce the friction and wear.

\section{Conclusions}

The HIF-MoS $/$ r-GO nanocomposite is directly filled into the PI coating during the preparation of polyamic acid precursors, followed by in situ polymerization and thermal imidization. Reinforcement in mechanical strength, thermal stability and tribological properties are realised on the HIF- $\mathrm{MoS}_{2} / \mathrm{r}-\mathrm{GO} / \mathrm{PI}$ nanocomposite coating. Reduced elastic modulus and hardness of HIF-MoS $2 / \mathrm{r}-\mathrm{GO} / \mathrm{PI}$ coating is increased by $8.3 \%$ and $4.8 \%$, respectively. The addition of HIF-MoS $/$ r-GO in PI also results in $24 \%$ higher residual mass at $800^{\circ} \mathrm{C}$ as compared to CNF. SEM images suggest that the ball-on-plate structure of $\mathrm{HIF-MoS} / \mathrm{r}$-GO may help form a robust protective barrier throughout the nanocomposite coating.

In terms of tribological properties, $\mathrm{HIF}-\mathrm{MoS}_{2} / \mathrm{r}-\mathrm{GO}$ achieves a wear rate reduction of $79 \%$ under dry sliding condition, which is much more effective than the other additives, including r-GO, $\mathrm{MoS}_{2}$ nanoparticles and CNF. Moreover, HIF-MoS $2 / \mathrm{r}-\mathrm{GO}$ still performs well at high temperature of $250{ }^{\circ} \mathrm{C}$, which can reduce the wear rate of PI coating by $53 \%$. Under the IL-lubricated condition, the PI coating shows much lower wear and friction coefficient than the dry sliding condition. It is exciting that adding HIF-MoS $2 / r-G O$ results in $30 \%$ reduction in wear rate and a $10 \%$ reduction in the friction coefficient. It indicates that the HIF-MoS $2 / \mathrm{r}$-GO in PI can in situ form a protective film during sliding; in this way the aggregation problem is successfully solved.

Author Contributions: Conceptualization and methodology, J.W. and Y.S.; investigation, writingoriginal draft preparation, and data curation, X.Y. and J.W.; writing-review and editing, J.W., L.M. and Y.S.; resources, X.F. and X.L.; supervision, X.L., X.F., and Y.S.; project administration and funding acquisition, J.W., X.L., and X.F. All authors have read and agreed to the published version of the manuscript.

Funding: This research was funded by: the National Natural Science Foundation of China (project numbers: Nos. 21908093, 21808102, 21838004, 91934302); the China Postdoctoral Science Foundation funded project (No. 2020M671461); VINNOVA (No. 2019-04866); the Swedish Kempe Scholarship Project (Nos. JCK-1740, JCK-1903.1); the Swedish Research Council for Environment, Agricultural Sciences and Spatial Planning (Formas, Nos. 2016-01098, 2019-00904); the Swedish Research Council (No. 2019-04941); and the Swedish Energy Agency (Energimyndigheten, Nos. 2017-008200, 2018-003910).

Institutional Review Board Statement: Not applicable.

Informed Consent Statement: Not applicable.

Data Availability Statement: The data presented in this study are available on request from the corresponding author.

Conflicts of Interest: The authors declare no conflict of interest.

\section{References}

1. Diez-Pascual, A.M.; Diez-Vicente, A.L. Nano-TiO 2 reinforced PEEK/PEI blends as biomaterials for load-bearing implant applications. ACS Appl. Mater. Interfaces 2015, 7, 5561-5573. [CrossRef] [PubMed]

2. Kurdi, A.; Kan, W.H.; Chang, L. Tribological behaviour of high performance polymers and polymer composites at elevated temperature. Tribol. Int. 2019, 130, 94-105. [CrossRef] 
3. Wang, Q.; Zheng, F.; Wang, T. Tribological properties of polymers PI, PTFE and PEEK at cryogenic temperature in vacuum. Cryogenics 2016, 75, 19-25. [CrossRef]

4. Wu, J.; Huang, X.; Berglund, K.; Lu, X.; Feng, X.; Larsson, R.; Shi, Y. CuO nanosheets produced in graphene oxide solution: An excellent anti-wear additive for self-lubricating polymer composites. Compos. Sci. Technol. 2018, 162, 86-92. [CrossRef]

5. Nunez, E.E.; Gheisari, R.; Polycarpou, A.A. Tribology review of blended bulk polymers and their coatings for high-load bearing applications. Tribol. Int. 2019, 129, 92-111. [CrossRef]

6. Min, C.; Nie, P.; Song, H.; Zhang, Z.; Zhao, K. Study of tribological properties of polyimide/graphene oxide nanocomposite films under seawater-lubricated condition. Tribol. Int. 2014, 80, 131-140. [CrossRef]

7. Huttunen-Saarivirta, E.; Yudin, V.E.; Myagkova, L.A.; Svetlichnyi, V.M. Corrosion protection of galvanized steel by polyimide coatings: EIS and SEM investigations. Prog. Org. Coat. 2011, 72, 269-278. [CrossRef]

8. Ye, X.; Liu, X.; Yang, Z.; Wang, Z.; Wang, H.; Wang, J.; Yang, S. Tribological properties of fluorinated graphene reinforced polyimide composite coatings under different lubricated conditions. Compos. Part A-Appl. S. 2016, 81, 282-288. [CrossRef]

9. Zhao, Y.; Qi, X.; Dong, Y.; Ma, J.; Zhang, Q.; Song, L.; Yang, Y.; Yang, Q. Mechanical, thermal and tribological properties of polyimide/nano-SiO 2 composites synthesized using an in-situ polymerization. Tribol. Int. 2016, 103, 599-608. [CrossRef]

10. Mu, L.; Zhu, J.; Fan, J.; Zhou, Z.; Shi, Y.; Feng, X.; Wang, H.; Lu, X. Self-lubricating polytetrafluoroethylene/polyimide blends reinforced with zinc oxide nanoparticles. J. Nanomater. 2015, 2015, 1-8. [CrossRef]

11. Xin, Y.; Xu, F.; Wang, M.; Li, T. Synergistic effects of carbon nanotube/nano-MoS 2 hybrid on tribological performance of polyimide nanocomposite films. Tribol. Lett. 2017, 66. [CrossRef]

12. Min, C.; Liu, D.; Shen, C.; Zhang, Q.; Song, H.; Li, S.; Shen, X.; Zhu, M.; Zhang, K. Unique synergistic effects of graphene oxide and carbon nanotube hybrids on the tribological properties of polyimide nanocomposites. Tribol. Int. 2018, 117, 217-224. [CrossRef]

13. Li, Y.; Wang, S.; Wang, Q. A molecular dynamics simulation study on enhancement of mechanical and tribological properties of polymer composites by introduction of graphene. Carbon 2017, 111, 538-545. [CrossRef]

14. Liu, D.; Zhao, W.; Liu, S.; Cen, Q.; Xue, Q. Comparative tribological and corrosion resistance properties of epoxy composite coatings reinforced with functionalized fullerene C60 and graphene. Surf. Coat. Technol. 2016, 286, 354-364. [CrossRef]

15. Liu, L.; Zhou, M.; Jin, L.; Li, L.; Mo, Y.; Su, G.; Li, X.; Zhu, H.; Tian, Y. Recent advances in friction and lubrication of graphene and other 2D materials: Mechanisms and applications. Friction 2019, 7, 199-216. [CrossRef]

16. Jenkins, P.; Siddique, S.; Khan, S.; Usman, A.; Starost, K.; MacPherson, A.; Bari, P.; Mishra, S.; Njuguna, J. Influence of reduced graphene oxide on epoxy/carbon fiber-reinforced hybrid composite: Flexural and shear properties under varying temperature conditions. Adv. Eng. Mater. 2019, 21, 1800614. [CrossRef]

17. Li, W.; Zhao, W.; Mao, L.; Zhou, S.; Liu, C.; Fang, Z.; Gao, X. Investigating the fluorination degree of FG nanosheets on the tribological properties of FG/PI composite coatings. Prog. Org. Coat. 2020, 139, 105481. [CrossRef]

18. Kalin, M.; Kogovšek, J.; Remškar, M. Mechanisms and improvements in the friction and wear behavior using $\mathrm{MoS}_{2}$ nanotubes as potential oil additives. Wear 2012, 280-281, 36-45. [CrossRef]

19. Yuan, H.; Liu, X.; Ma, L.; Yang, Z.; Wang, H.; Wang, J.; Yang, S. Application of two-dimensional MoS $_{2}$ nanosheets in the property improvement of polyimide matrix: Mechanical and thermal aspects. Compos. Part A-Appl. S. 2017, 95, 220-228. [CrossRef]

20. Yuan, H.; Yang, S.; Liu, X.; Wang, Z.; Ma, L.; Hou, K.; Yang, Z.; Wang, J. Polyimide-based lubricating coatings synergistically enhanced by $\mathrm{MoS}_{2} @$ HCNF hybrid. Compos. Part A-Appl. S. 2017, 102, 9-17. [CrossRef]

21. Xin, Y.; Li, T.; Gong, D.; Xu, F.; Wang, M. Preparation and tribological properties of graphene oxide/ nano-MoS $_{2}$ hybrid as multidimensional assembly used in the polyimide nanocomposites. RSC Adv. 2017, 7, 6323-6335. [CrossRef]

22. Wu, J.; Mu, L.; Zhu, J.; Feng, X.; Lu, X.; Larsson, R.; Shi, Y. Synthesis of hollow fullerene-like molybdenum disulfide/reduced graphene oxide nanocomposites with excellent lubricating properties. Carbon 2018, 134, 423-430. [CrossRef]

23. Rapoport, L.; Nepomnyashchy, O.; Verdyan, A.; Popovitz-Biro, R.; Volovik, Y.; Ittah, B.; Tenne, R. Polymer nanocomposites with fullerene-like solid lubricant. Adv. Eng. Mater. 2004, 6, 44-48. [CrossRef]

24. Loy, X.Z.K.; Sinha, S.K. Lubrication of polyether ether ketone (PEEK) surface by liquid ultrathin films for high wear durability. Wear 2012, 296, 681-692. [CrossRef]

25. Shi, Y.; Mu, L.; Feng, X.; Lu, X. Friction and Wear Behavior of CF/PTFE composites lubricated by choline chloride ionic liquids. Tribol. Lett. 2013, 49, 413-420. [CrossRef]

26. Wu, J.; Zhu, J.; Mu, L.; Shi, Y.; Dong, Y.; Feng, X.; Lu, X. High load capacity with ionic liquid-lubricated tribological system. Tribol. Int. 2016, 94, 315-322. [CrossRef]

27. Wu, J.; Lu, X.; Feng, X.; Shi, Y. Halogen-free ionic liquids as excellent lubricants for PEEK-stainless steel contacts at elevated temperatures. Tribol. Int. 2016, 104, 1-9. [CrossRef]

28. Zhao, F.; Li, G.; Zhang, G.; Wang, T.; Wang, Q. Hybrid effect of ZnS sub-micrometer particles and reinforcing fibers on tribological performance of polyimide under oil lubrication conditions. Wear 2017, 380-381, 86-95. [CrossRef]

29. Yin, X.; Wu, J.; Li, C.; Lu, X.; Feng, X.; Shi, Y. Right way of using graphene oxide additives for water-lubricated PEEK: Adding in polymer or water? Tribol. Lett. 2018, 66. [CrossRef]

30. Wang, X.B.; Liu, W.M. Nanoparticle-based lubricant additives. In Encyclopedia of Tribology; Wang, Q.J., Chung, Y.-W., Eds.; Springer: New York, NJ, USA, 2013; pp. 2369-2376. ISBN 978-0-387-92898-2. 
31. Zhu, J.; Feng, X.; Shi, Y.; Wang, H.; Lu, X. Tribological and mechanical properties of carbon nanofiber-filled polytetrafluoroethylene/polyimide composites. J. Nanosci. Nanotechnol. 2009, 9, 5958-5965. [CrossRef]

32. Shi, Y.; Feng, X.; Wang, H.; Lu, X.; Shen, J. Tribological and mechanical properties of carbon-nanofiber-filled polytetrafluoroethylene composites. J. Appl. Polym. Sci. 2007, 104, 2430-2437. [CrossRef]

33. Shi, Y.; Li, C.; He, D.; Shen, L.; Bao, N. Preparation of graphene oxide-cellulose acetate nanocomposite membrane for high-flux desalination. J. Mater. Sci. 2017, 52, 13296-13306. [CrossRef]

34. Zhou, K.; Jiang, S.; Shi, Y.; Liu, J.; Wang, B.; Hu, Y.; Gui, Z. Multigram-scale fabrication of organic modified MoS $_{2}$ nanosheets dispersed in polystyrene with improved thermal stability, fire resistance, and smoke suppression properties. RSC Adv. 2014, 4, 40170-40180. [CrossRef]

35. Dong, F.; Hou, G.; Cao, F.; Yan, F.; Liu, L.; Wang, J. The lubricity and reinforcement of carbon fibers in polyimide at high temperatures. Tribol. Int. 2016, 101, 291-300. [CrossRef] 